Article

\title{
Effect of Basicity on Sintering Behavior and Metallurgical Properties of High-Chromium Vanadium-Titanium Magnetite
}

\author{
Liheng Zhang ${ }^{1, *} \mathbb{C}$, Zixian Gao ${ }^{1}$, Songtao Yang ${ }^{2}$, Weidong Tang ${ }^{1}$ and Xiangxin Xue ${ }^{1, *}$ \\ 1 School of Metallurgy, Northeastern University, Shenyang 110819, China; gaozixian1992@163.com (Z.G.); \\ tangwderos@163.com (W.T.) \\ 2 School of Material and Metallurgy, University of Science and Technology Liaoning, Anshan 114051, China; \\ yangsongtao1984@163.com \\ * Correspondence: zhanglihengchn@gmail.com (L.Z.); xuexx@mail.neu.edu.cn (X.X.); \\ Tel.: +86-024-83687719 (X.X.)
}

Received: 7 April 2020; Accepted: 25 April 2020; Published: 27 April 2020

\begin{abstract}
Basicity has an important effect on the behavior of high-chromium vanadium-titanium magnetite (HCVTM) sinter. The effect of basicity on sintering, reduction, and softening-melting properties was investigated in an experiment-scale sinter pot. The results showed that with the basicity increasing from 1.7 to 2.5 , the vertical sinter speed, the productivity, the particle size, the reduction disintegration index (RDI), and the reducibility index (RI) increased. The yield increased first and then decreased, while the tumble index (TI) had the opposite trend. The perovskite content increased first and then stabilized, and the silico-ferrite of calcium and aluminum (SFCA) increased from the basicity of 2.3. The HCVTM sinter had a better tendency of the softening behavior with the basicity increase. In addition, the melt droplet comprehensive index $S$ increased, which indicated that the increase in basicity negatively affected the droplet performance. As the basicity increased, the comprehensive index value increased. Considering the adverse effect of basicity on softening-melting properties, the best recommended value is 2.3 .
\end{abstract}

Keywords: basicity; high-chromium vanadium-titanium magnetite; sinter; metallurgical property

\section{Introduction}

In recent years, a kind of high-chromium vanadium-titanium magnetite (HCVTM) was discovered in Hongge Town, Sichuan Province, China, and the reserves exceed 3.6 billion tons. The similar ores were mainly distributed in Canada, Russia, Australia, and other places [1,2]. High-chromium vanadium-titanium magnetite (HCVTM) containing various kinds of valuable elements $(\mathrm{Fe}, \mathrm{Ti}, \mathrm{Cr}$, and V) can satisfy the need for Ti, Cr, and V metals, as well as their alloys [3,4]. HCVTM has a high valuable element content, which shows a comprehensive utilization value. Iron ore concentrates cannot be charged into the blast furnace (BF) directly because of the detriment to the permeability of the furnace. Therefore, iron ore fines need to be agglomerated into larger pieces. Sintering is one of the most economical and widely used method for preparing iron ore fines for the BF. Many physical and chemical reactions of the mixture may occur during the sintering process.

Basicity $\left(\mathrm{CaO} / \mathrm{SiO}_{2}\right)$ is one of the most important control parameters in the sintering process and has been studied by domestic and foreign researchers [5-7]. It affects both the sintering process and the yield and quality of sinter, as well as the reduction process and the BF charge structure in BF smelting [8-11]. Wang [8] studied the effect and function mechanism of sinter basicity on softening-melting behaviors of mixed burden made from chromium-bearing vanadium-titanium magnetite, which confirmed that the proper sinter basicity value is not lower than 2.13 for smelting mixed burden in the BF. Yu [9] 
studied the effect of basicity on the titanomagnetite concentrate sinter and concluded that adjusting sinter basicity can restrain the adverse effect of $\mathrm{TiO}_{2}$ on sintering of titanomagnetite concentrates. Umadevi [10] studied the influence of sinter basicity on low- and high-alumina iron ore sinter quality. Studies have been carried out on low- and high-alumina iron ore fines to find out the influence of sinter basicity increase on sinter mineralogy, properties, and productivity. Zhou [11] studied the influence of basicity on Russian chromium-bearing vanadium-titanium magnetite sinter properties, which confirmed that the optimal basicity value for industrial application was 2.55 . Furthermore, the abovementioned studies on sinter properties affected by basicity concentrated on ordinary iron ore sinter and some titaniferous magnetite sinter.

In this work, the aim is to reveal the effect of basicity on the HCVTM sinter in Hongge Town via the sinter pot test. The sinter properties were then tested and calculated. The effects of basicity on reduction, mineralogy, and softening-melting properties were analyzed. The study on sinter basicity of the HCVTM sinter provides a theoretical basis and technical support for BF smelting HCVTM and promotes smelting and energy saving in the pre-alloying process.

\section{Materials and Methods}

\subsection{Materials}

The HCVTM iron ore was from Hongge Town (Panzhihua City, China). It has a high $\mathrm{Cr}_{2} \mathrm{O}_{3}$ $(0.55 \mathrm{wt} \%)$ and $\mathrm{TiO}_{2}(11.01 \mathrm{wt} \%)$ content. Ordinary magnetite (OM), gas-ash (GA), magnetic powder (MP), lime, return mine (RM), and coke were supplied by the Chengde Jianlong Iron and Steel Group Company (Hebei, China). The chemical composition was shown in Table 1. In addition, the XRD of the raw materials was reported previously [12].

Table 1. The chemical compositions of raw materials (wt $\%$ ).

\begin{tabular}{cccccccccccc}
\hline $\begin{array}{c}\text { Raw } \\
\text { Materials }\end{array}$ & $\mathbf{T F e}$ & $\mathbf{F e O}$ & $\mathrm{TiO}_{2}$ & $\mathbf{V}_{\mathbf{2}} \mathbf{O}_{\mathbf{5}}$ & $\mathrm{Cr}_{\mathbf{2}} \mathbf{O}_{3}$ & $\mathbf{C a O}$ & $\mathrm{SiO}_{2}$ & $\mathbf{M g O}$ & $\mathrm{Al}_{2} \mathbf{O}_{3}$ & $\mathbf{P}$ & $\mathbf{S}$ \\
\hline HCVTM & 56.45 & 28.05 & 11.01 & 0.37 & 0.55 & 0.63 & 2.66 & 2.54 & 2.42 & 0.003 & 0.34 \\
GA & 32.39 & - & 1.79 & 0.25 & 0.16 & 5.16 & 5.95 & 1.79 & 2.69 & 0.070 & 0.17 \\
MP & 0.14 & - & 0.03 & - & - & 29.4 & 2.58 & 20.65 & 0.90 & - & - \\
OM & 63.79 & 28.35 & 0.89 & 0.06 & 0.02 & 0.38 & 7.15 & 0.38 & 1.25 & 0.020 & 0.05 \\
Quicklime & - & - & - & - & - & 60.80 & 3.42 & 2.87 & 1.11 & - & - \\
\hline
\end{tabular}

\subsection{Apparatus and Procedure}

According to the actual situation of the raw materials, the experimental schedule was designed, as shown in Table 2 . The basicity was adjusted from $1.7 \%$ to $2.5 \%$ with adding different contents of quicklime. The $\mathrm{MgO}$ content was adjusted to $2.0 \%$ by magnesite, the $\mathrm{SiO}_{2}$ content was about $4.8 \%$, and the coke content was fixed at $4.5 \%$. The sintering test involves blending, mixing, granulating, igniting, sintering, cooling, pulverizing, and treatment of the cooled sinter. First, $100 \mathrm{~kg}$ raw materials are granulated in a drum with a diameter of $1 \mathrm{~m}$ for $10 \mathrm{~min}$. After mixing, the sinter mixture was placed in the sinter pot and ignited at $1000{ }^{\circ} \mathrm{C}$ for $2 \mathrm{~min}$, then it was sintered until the temperature of the flue gas reached the end of the peak; after that the agglomerate was cooled for $20 \mathrm{~min}$ and discharged. The sintering test parameters remained fixed throughout the experiment as listed in Table 3. The analysis methods were described previously [13]. 
Table 2. Experimental scheme and ingredients of sinter materials (wt $\%)$.

\begin{tabular}{ccccccc}
\hline \multirow{2}{*}{ Basicity } & \multicolumn{6}{c}{ Mixed Sinter Raw Materials } \\
\cline { 2 - 7 } & HCVTM & OM & RM & GA & MP & Quicklime \\
\hline 1.7 & 39.8 & 30.0 & 20.0 & 1.0 & 1.0 & 8.2 \\
1.9 & 38.2 & 30.0 & 20.0 & 1.0 & 1.0 & 9.8 \\
2.1 & 36.3 & 30.0 & 20.0 & 1.0 & 1.0 & 11.7 \\
2.3 & 35.4 & 30.0 & 20.0 & 1.0 & 1.0 & 12.6 \\
2.5 & 33.8 & 30.0 & 20.0 & 1.0 & 1.0 & 14.2 \\
\hline
\end{tabular}

Table 3. Parameters of the high-chromium vanadium-titanium magnetite (HCVTM) sinter pot test.

\begin{tabular}{cccc}
\hline Item & Parameter & Item & Parameter \\
\hline Sinter pot height & $700 \mathrm{~mm}$ & Sinter pot inner diameter & $320 \mathrm{~mm}$ \\
Sinter weight & $100 \mathrm{~kg}$ & Pelletizing time & $10 \mathrm{~min}$ \\
Ignition temperature & $1000^{\circ} \mathrm{C}$ & Ignition time & $2 \mathrm{~min}$ \\
Height of grate layer & $20 \mathrm{~mm}$ & Moisture & $10.0 \pm 0.5 \%$ \\
Ignition pressure & $8.00 \mathrm{kPa}$ & Exhausting pressure & $12.0 \mathrm{kPa}$ \\
\hline
\end{tabular}

\subsection{Definition of Parameters}

\subsubsection{Vertical Sinter Speed}

The vertical sinter speed (VSS) is an index to indicate the sintering rate. The calculation equation of VSS is given in Equation (1):

$$
V S S=\frac{L}{T}
$$

where $L$ is the thickness of the raw material $(\mathrm{mm}), T$ is the sintering time (min).

\subsubsection{Tumbler Index}

The tumbler index (TI) is an important index for evaluating the impact resistance of the sinter. According to the international standard ISO 3217-2007, the equation of TI is given in Equation (2):

$$
T I=\frac{m_{1}}{m_{0}} \times 100 \%
$$

where $\mathrm{m}_{0}$ is the sample weight in the drum $(\mathrm{g}), \mathrm{m}_{1}$ is the sinter weight on the $6.3 \mathrm{~mm}$ sieve $(\mathrm{g})$.

\subsubsection{Productivity}

The productivity was calculated using Equation (3):

$$
P=M_{S} \times y /(A \times t)
$$

where $P$ is the unit productivity $\left(\mathrm{t} \cdot \mathrm{m}^{-2} \cdot \mathrm{h}^{-2}\right), M_{S}$ is the mass of sinter cake $(\mathrm{t}), y$ is the yield of product sinter (\%), $A$ is the cross-section area of sinter pot $\left(\mathrm{m}^{2}\right)$, and $t$ is the sintering time $(\mathrm{h})$.

\subsubsection{Reduction Disintegration Index}

The reduction disintegration index (RDI) is a measure of the disintegration property of sinter on the exposure to $\mathrm{CO}$ at $500{ }^{\circ} \mathrm{C}$. The equations of RDI are given in Equations (4)-(6):

$$
\begin{gathered}
R D I_{+6.3}=\frac{m_{D 1}}{m_{D 0}} \times 100 \\
R D I_{+3.15}=\frac{m_{D 1}+m_{D 2}}{m_{D 0}} \times 100
\end{gathered}
$$




$$
R D I_{-0.5}=\frac{m_{D 0}-\left(m_{D 1}+m_{D 2}+m_{D 3}\right)}{m_{D 0}} \times 100
$$

where $m_{\mathrm{D} 0}$ is the sinter weight after the reduction $(\mathrm{g}), m_{\mathrm{D} 1}$ is the sinter weight on the $6.3 \mathrm{~mm}$ sieve $(\mathrm{g})$, $m_{\mathrm{D} 2}$ is the sinter weight on the $3.15 \mathrm{~mm}$ sieve $(\mathrm{g})$, and $m_{\mathrm{D} 3}$ is the sinter weight on the $0.5 \mathrm{~mm}$ sieve $(\mathrm{g})$.

\subsubsection{Reducibility Index}

The reducibility index (RI) is determined by the ISO-7215 test performed at $900{ }^{\circ} \mathrm{C}$. The equations of RDI are given in Equation (7):

$$
X_{\mathrm{t}}=\left[\frac{0.11 \omega(\mathrm{FeO})}{0.43 \omega(\mathrm{TFe})}+\frac{m_{1}-m_{2}}{m_{1} \times 0.43 \omega(\mathrm{TFe})}\right] \times 100 \%
$$

where $X_{\mathrm{t}}$ is the RI of HCVTM sinter at time $t(\%), \omega(\mathrm{FeO})$ and $\omega(\mathrm{TFe})$ are the mass of FeO and total ferrous of HCVTM sinter before reduction (\%); $m_{1}$ and $m_{2}$ are the mass of HCVTM sinter before reduction $(\mathrm{g})$.

\subsubsection{Softening-Melting Properties}

The softening-melting properties of the sinter have a significant effect on the reduction process and the permeability of the load. In this work, the softening start temperature $\left(\mathrm{T}_{10 \%}\right)$ and softening end temperature $\left(\mathrm{T}_{40 \%}\right)$ are the burden temperature when the shrinkage degree reaches $10 \%$ and $40 \%$, respectively. The melting start temperature $\left(\mathrm{T}_{\mathrm{s}}\right)$ is the temperature that the gas pressure drop begins to increase rapidly. The melting end temperature $\left(T_{d}\right)$ is the dripping temperature of iron. The softening zone of sinter is the softening temperature interval $\left(\Delta \mathrm{T}_{1}=\mathrm{T}_{40 \%}-\mathrm{T}_{10 \%}\right)$. The melting zone of sinter is the melting temperature interval $\left(\Delta \mathrm{T}_{2}=\mathrm{T}_{\mathrm{d}}-\mathrm{T}_{\mathrm{s}}\right)$.

A characteristic value $S$ is introduced to evaluate the dripping performance of the sinter. The smaller the $S$, the better the droplet performance. The equation of $S$ is given in Equation (8):

$$
\mathrm{S}=\int_{\mathrm{T}_{\mathrm{s}}}^{\mathrm{T}_{\mathrm{d}}}\left(\Delta P_{m}-\Delta P_{s}\right) \cdot d t
$$

where $\Delta \mathrm{Ps}$ is the starting melting pressure difference, in which the value is $50 \times 9.8 \mathrm{~Pa} ; \Delta \mathrm{P}_{\mathrm{m}}$ is the maximum pressure difference, $\mathrm{Pa}$.

\section{Results and Discussion}

\subsection{Effect of Basicity on Sinter Properties}

Figure 1 shows the sinter properties for different basicity. With the basicity increasing from 1.7 to 2.5 , the VSS increased from 15.81 to $17.89 \mathrm{~mm} \cdot \mathrm{min}^{-1}$. On the one hand, HCVTM has a small specific surface area and poor hydrophilicity, which can be compensated to some extent, improving the granulation conditions and the sphericity of the mixture. The gas permeability of the sinter improves. On the other hand, quicklime is slaked into hydrated lime $\mathrm{Ca}(\mathrm{OH})_{2}$ upon contact with water in the sinter during the mixing and granulation stages. The exothermic hydration reactions increase the sinter mixture temperature, and the granulation is improved by the $\mathrm{Ca}(\mathrm{OH})_{2}$ bonding, which can assist condensation in the bottom layer of the sinter bed and improve the granule strength [14,15]. These changes decrease the sintering resistance and increase the sintering rate [11]. Based on the abovementioned factors, as the basicity increased, the VSS increased.

The yield and the TI had the opposite trend. When the basicity increased from 1.7 to 2.1 , the yield increased from $71.14 \%$ to $81.74 \%$ and the TI decreased from $48.3 \%$ to $46.0 \%$. However, as the basicity value increased from 2.1 to 2.5 , the yield decreased from $81.74 \%$ to $79.00 \%$ and the TI increased from $46.0 \%$ to $49.3 \%$. Under the premise that the solid fuel dosage remained unchanged, as the basicity increased, the melting dose increased gradually, and the formation of low-melting minerals increased 
in the sinter. Therefore, the amount of liquid phase formation increased. As a result, the yield increased. This is because when more lime in the iron ore fines was added, the contact between $\mathrm{CaO}$ and the other main mineral components such as $\mathrm{Fe}_{2} \mathrm{O}_{3}, \mathrm{SiO}_{2}, \mathrm{TiO}_{2}$, and others increased, and the kinetic conditions were improved during the heating process. At the same time, with the further increase of quicklime, the sinter grade was reduced and the loss on ignition became greater. What is more, the sinter speed was increased, which led to a shorter crystallization time, which affected the yield of sinter ore and caused a decrease in the yield. As the basicity increased, the sinter TI decreased first and then increased. During the sintering process, basicity had a great influence on the sintering process and the composition of the sintered binder phase. The binding ability of $\mathrm{TiO}_{2}$ and $\mathrm{CaO}$ was stronger than that of $\mathrm{Fe}_{2} \mathrm{O}_{3}$ and $\mathrm{CaO}$. When the basicity was low, $\mathrm{CaO}$ formed perovskite with $\mathrm{TiO}_{2}$. With the increase of basicity, the perovskite increased gradually and the strength of sinter gradually deteriorated. After all the $\mathrm{TiO}_{2}$ formed perovskite, as the basicity increased, both the calcium ferrite and the strength of the sinter increased as well. Productivity which was determined by the sinter speed and the sinter yield increased from 1.33 to $1.54 \mathrm{t} \cdot \mathrm{m}^{-2} \cdot \mathrm{h}^{-1}$.

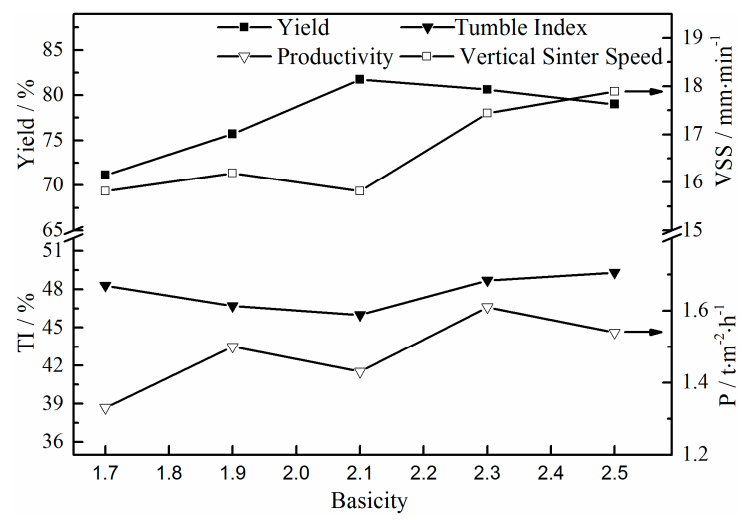

Figure 1. Effect of basicity on sinter properties.

The size distribution of HCVTM sinter with different basicity is shown in Figure 2. The proportion of particles with a size bigger than $16 \mathrm{~mm}$ increased from $39 \%$ to $53 \%$ with the basicity increasing from 1.7 to 2.5, which indicated that the particles of HCVTM sinter were mostly large particles. The increase of the liquid phase and the sinter strength were the reason for the larger particle formation.

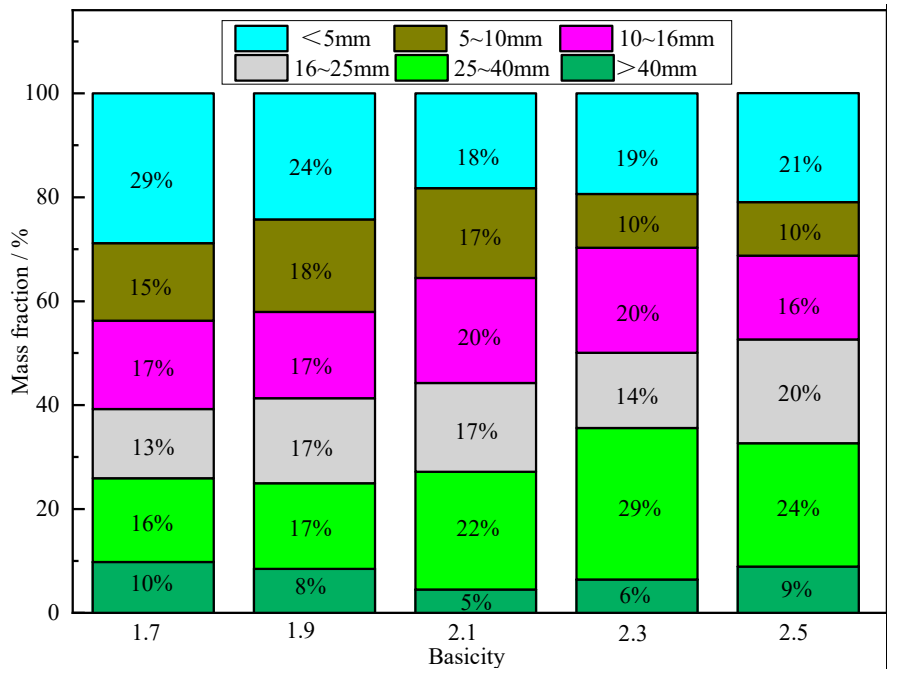

Figure 2. Particle size distribution of HCVTM sinters with different basicity.

According to the analysis of the XRD pattern of the HCVTM sinters (Figure 3), the main mineral phases of the HCVTM sinter were magnetite $\left(\mathrm{Fe}_{3} \mathrm{O}_{4}\right)$, hematite $\left(\mathrm{Fe}_{2} \mathrm{O}_{3}\right)$, perovskite $(\mathrm{CaTiO})$, etc. 
The peak intensity of perovskite became stronger with the basicity increase, and the silico-ferrite of calcium and aluminum (SFCA) was generated as the basicity reached 2.3. Meanwhile, the magnesium ferrite $\left(\mathrm{MgFe}_{2} \mathrm{O}_{4}\right)$ was generated because of the similar ionic radii of $\mathrm{Mg}^{2+}(0.78 \AA)$ and the Fe ${ }^{2+}(0.83 \AA)$. Several low-intensity peaks appeared, which can be attributed to the solid solutions of $\left(\mathrm{Fe}_{0.6} \mathrm{Cr}_{0.4}\right)_{2} \mathrm{O}_{3}$ and $\left(\mathrm{Cr}_{0.15} \mathrm{~V}_{0.85}\right)_{2} \mathrm{O}_{3}$.

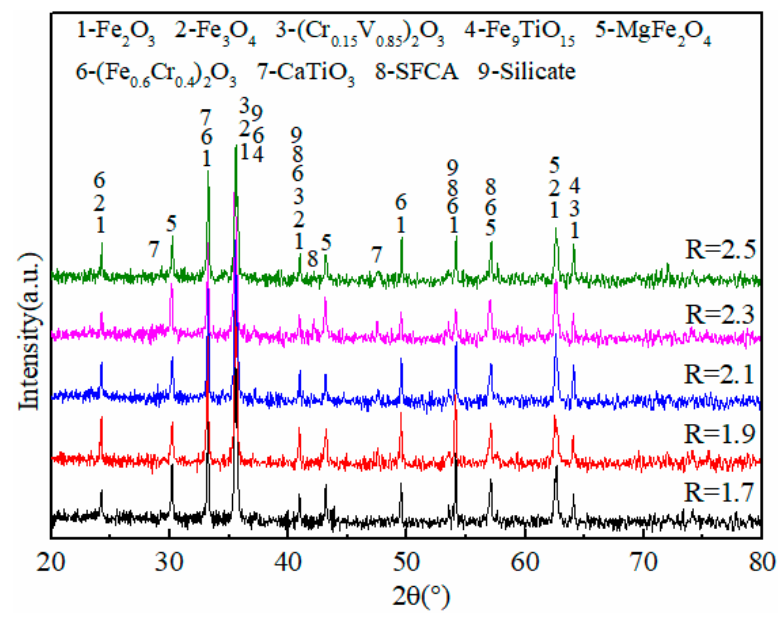

Figure 3. XRD pattern of HCVTM sinters with different basicity.

Figure 4 shows the microstructure of the HCVTM sinter with different basicity. The mineral structure changed significantly with the increasing basicity. The main mineral phases were titanomagnetite, titanohematite, perovskite, and silicate. Figure 4A shows that the mineral phases were mainly symbiotic structures and partially eutectic structures. The magnetite in the sinter was irregularly distributed in other crystals, and some magnetite and hematite were paragenetic minerals, and the bonding phase was mostly vitreous and silicate minerals. With the basicity increased to 1.9 (Figure 4B), the liquid phase increased, and the crystallization of the perovskite phases mainly existed in the silicate phases in the form of a solid solution, and the perovskite had little effect on the bonding phase of the silicate phases and the crystal strength between hematite and magnetite [16,17]. The grains of hematite and magnetite were refined, as shown in Figure 4C. The SFCA appeared near the hematite phase and mixed with other liquid phases. Figure 4D shows that the dendritic perovskite was distributed in the silicates uniformly. Figure 4E shows that the mineralogical structure was not uniform, with interwoven dissolution structures as the main structures, and some being skeleton crystal structures.

The morphology of the perovskite depended mainly on the thermal level and the element content of the sinter. Four different types of perovskite were observed, namely granular structure, columnar structure, dendritic structure, and corrosion lamellar structure, as shown in Figure 4. Granular structures were found in the sinter with a low lime content in Figure 4A. Granular and columnar structures were the main structures for higher basicity, as shown in Figure 4B,C. With the increase of basicity, the type of dendritic structure that predominated in Figure 4D appeared. Corrosion lamellar structures were found in Figure 4E. The perovskite content was the reason for the sinter cold strength and the RI.

On the one hand, adding more limestone to the sinter brought about an increase in the extent of perovskite formation [18], as can be seen from the results of the quantitative analysis shown in Figure 5. The main minerals were titanomagnetite and titanohematite, which decreased with the increase of basicity. The perovskite content first increased, but when the basicity was 2.1, it began to stabilize, while the SFCA increased rapidly. On the other hand, more limestone meant more endothermic $\mathrm{CaCO}_{3}$ decomposition reactions. The low sinter temperature benefited the generation of SFCA but was unfavorable for the formation of perovskite. 

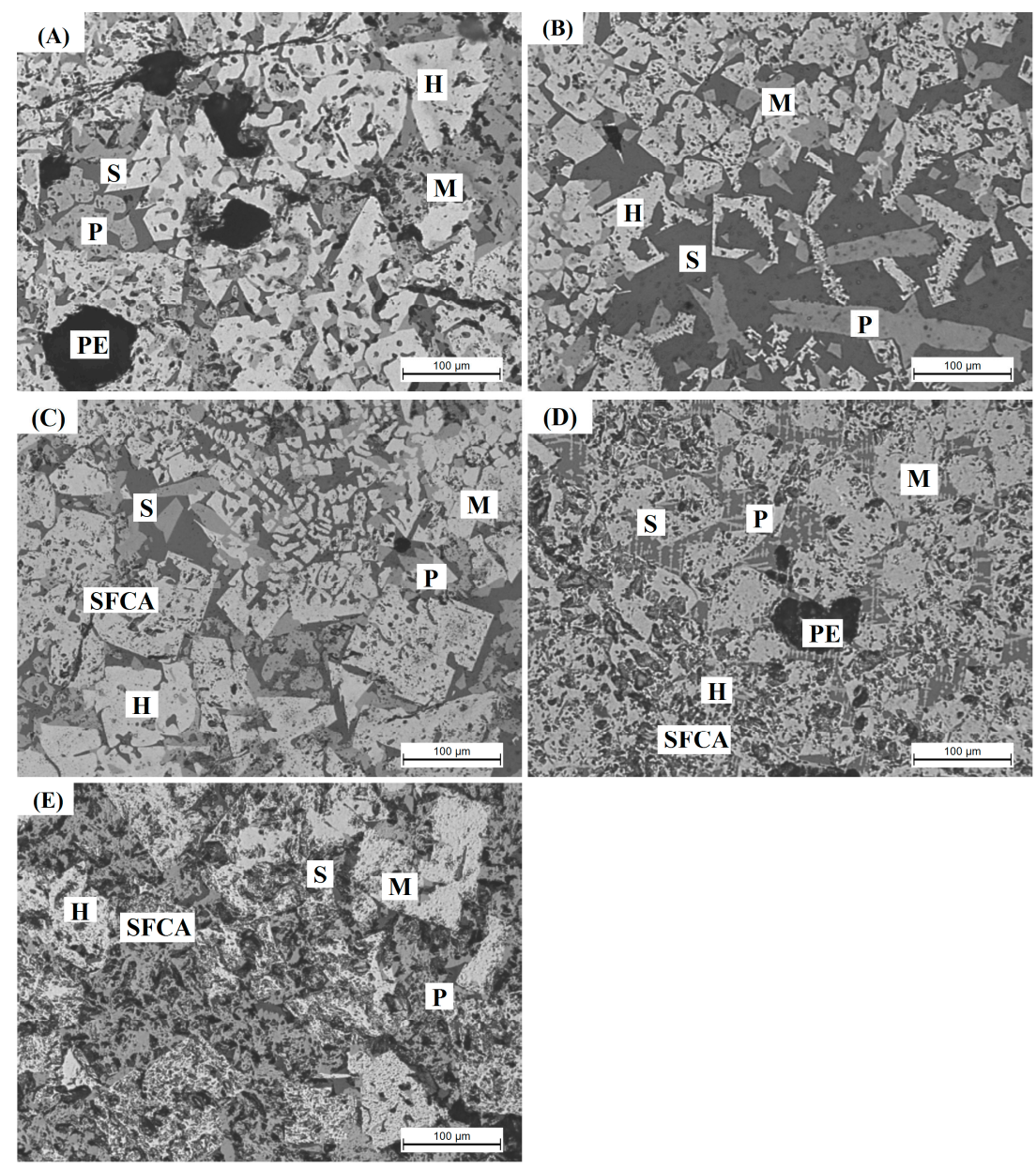

Figure 4. Microstructure of HCVTM sinters with different basicity. (A) $\mathrm{R}=1.7$; $(\mathrm{B}) \mathrm{R}=1.9$; (C) $\mathrm{R}=2.1$; (D) $\mathrm{R}=2.3 ;(\mathrm{E}) \mathrm{R}=2.5$. H: Hematite; M: Magnetite; P: Perovskite; S: silicate; PE: Pore.

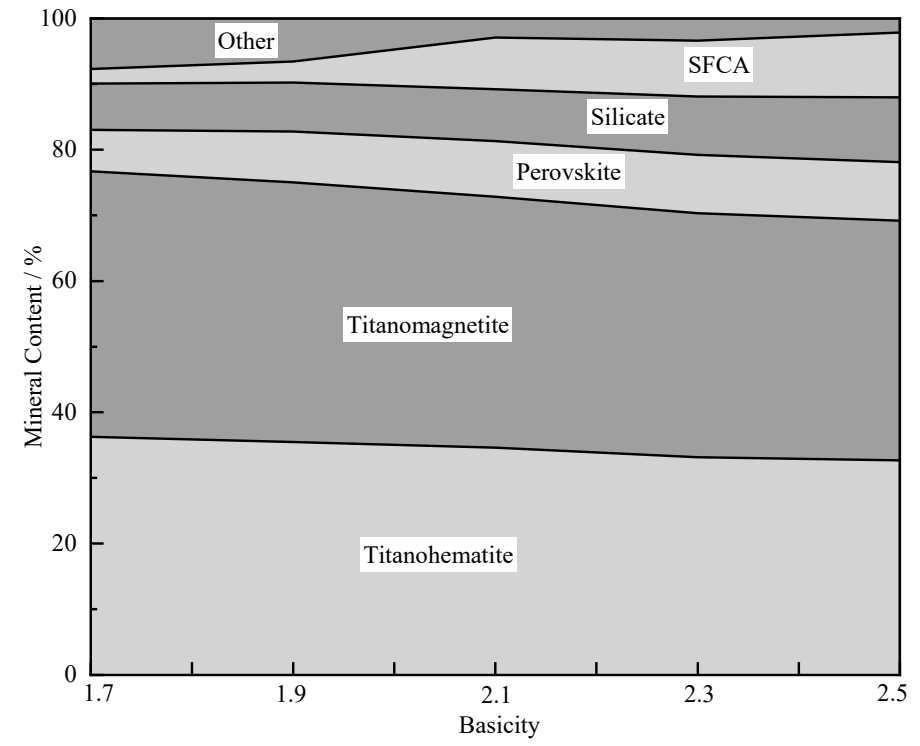

Figure 5. Effect of basicity on the mineral composition of HCVTM sinters.

In addition to characterization of the sinter using conventional microscopy, the microanalysis of different phases was carried out using the SEM image and EDS mapping to determine the chemical composition distribution of the various mineralogical constituents of the sinter. The results are summarized as follows and can be seen from Figure 6. It can be seen that the sinter was mainly 
composed of magnetite, calcium silicate, and perovskite. The magnetite was idiomorphic and hypidiomorpic crystals, which was unevenly distributed. As a result of the high calcium content in the sinter, the perovskite content was high. It was distributed between iron oxides and was the main bonding phase. The silicate content was very low. The distribution of $\mathrm{Mg}^{2+}$ and $\mathrm{Fe}^{3+}$ was consistent. $\mathrm{Mg}^{2+}$ was rarely distributed in the perovskite and the calcium silicate. $\mathrm{The} \mathrm{Ca}^{2+}, \mathrm{Ti}^{4+}$, and $\mathrm{Si}^{4+}$ were mainly distributed and dissolved in the slag and the liquid phases. The distribution of $\mathrm{V}^{4+}$ was consistent with that of $\mathrm{Ti}^{4+}$, while the distribution of $\mathrm{Cr}^{3+}$ was disordered and in each phase. $\mathrm{Mg}^{2+}$ was mainly distributed in the magnetite and hematite phases, and it was negligible in the perovskite and silicate phases. Perovskite was observed in the gaps between joined crystals of titanomagnetite or titanohematite.
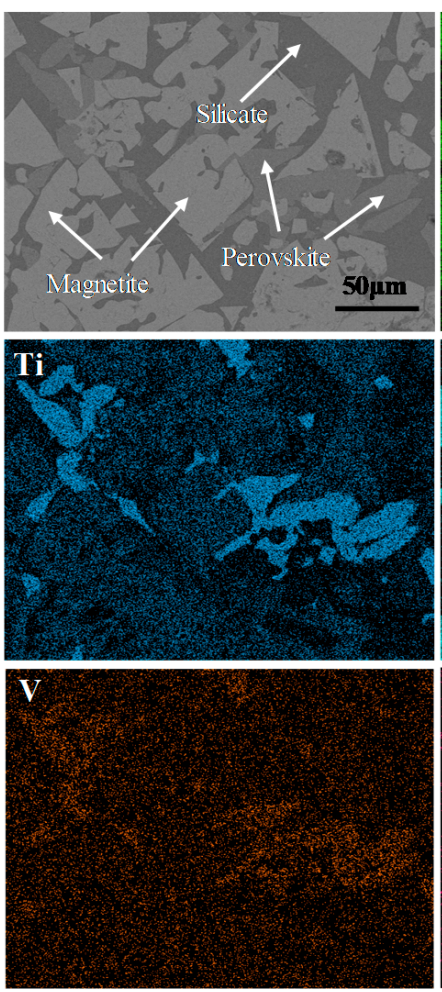
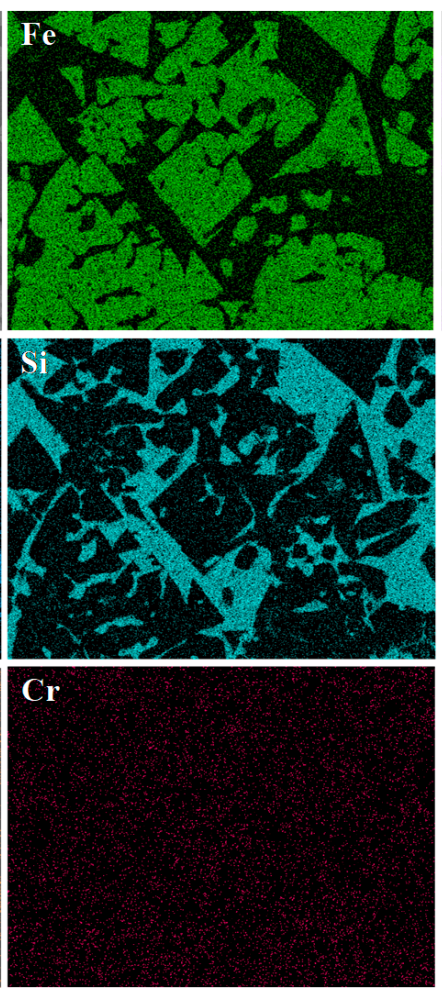
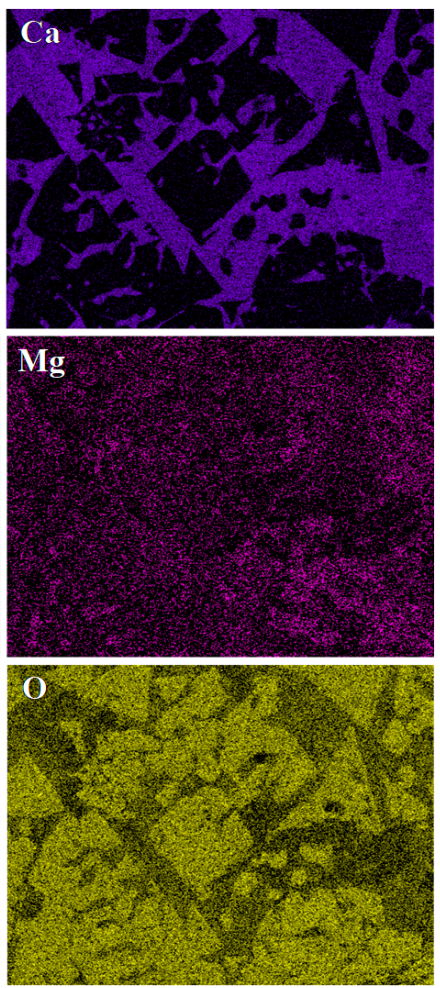

Figure 6. SEM image and EDS mapping of HCVTM sinters (basicity = 2.3).

\subsection{Effect of Basicity on Reduction Properties}

Figure 7 shows the RDI and the RI of the HCVTM sinter with different basicity. With the increase of sinter basicity, the RDI of the sinter increased greatly, that is, the reduction pulverization performance of the sinter was improved. The main reason was that the calcium ferrite content in the sinter increased significantly, and the titanium hematite content was reduced, which reduced the volume expansion of hematite reduction to magnetite. The calcium ferrite in the sinter increased, that is, the binder phase increased. The reduction process was inhibited by the decrease of hematite and the regenerated hematite content. At the same time, the high-basicity sinter promoted the formation of $3 \mathrm{CaO} \cdot \mathrm{SiO} \mathrm{O}_{2}$, which reduced the calcium orthosilicate, and promoted the dispersion of calcium orthosilicate in the binder phase of calcium ferrite, inhibiting volume expansion. Figure 8 shows the sinter SEM image following reduction at $500{ }^{\circ} \mathrm{C}$ for $60 \mathrm{~min}$. The disintegration and cracks occurred during the crystalline transformation. The mineralogical structures of the sinter were mainly titanomagnetite, calcium ferrite, perovskite, and silicate. 


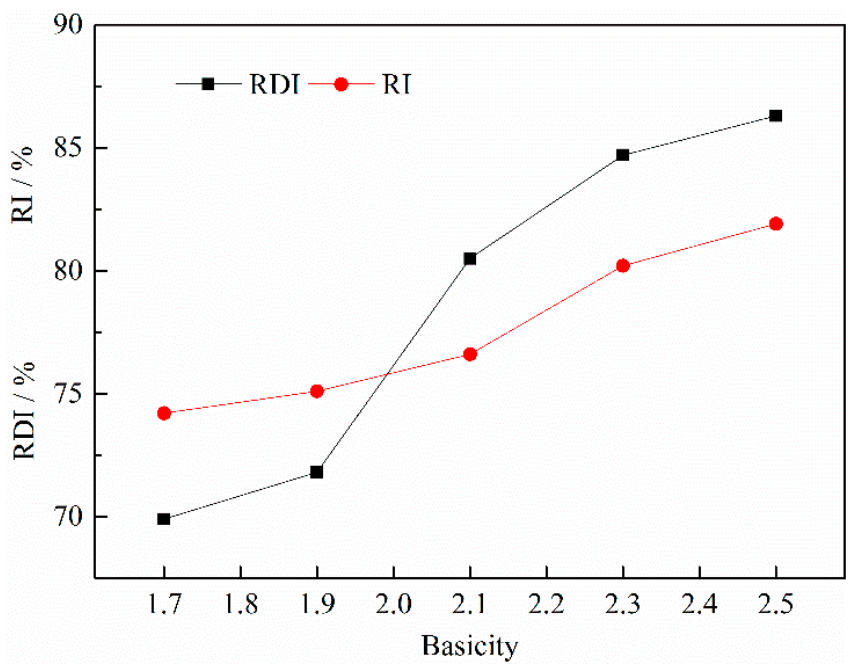

Figure 7. Reduction disintegration index (RDI) and reducibility index (RI) of HCVTM sinters with different basicity.

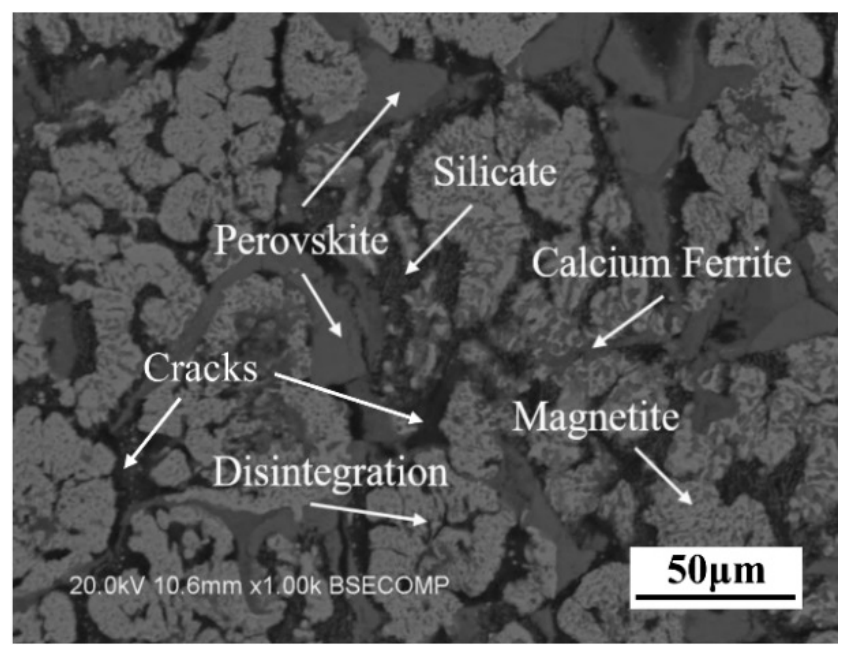

Figure 8. Reduction sinter at $500{ }^{\circ} \mathrm{C}$ for $60 \mathrm{~min}$ (basicity $=2.1$ ).

The RI, as the principal indicator for evaluating the metallurgical property of the sinter, is used to simulate the condition for feeding the load from the top of the BF to a high-temperature zone. What is more, it could show the difficulty level of the gas reductant capturing the combination of oxygen and iron in the sinter. The sinter had a good reducing property, which was beneficial to strengthening smelting, and therefore, decreased reductant consumption and the coke ratio. As shown in Figure 7 , when the basicity increased from 1.7 to 2.5 , the RI increased from $74.2 \%$ to $81.9 \%$. According to the mineral phase analysis of the HCVTM sinter, the calcium ferrite, which was easy to be reduced increased while $2 \mathrm{FeO} \cdot \mathrm{SiO}_{2}$ decreased with the increasing basicity. In the sinter process, the permeability, the flow rate, and the cooling rate decreased with the increasing basicity, and so did the FeO content. The RI of the sinter increased with the decreasing FeO [19].

Figure 9 shows the SEM image and EDS analysis of the HCVTM sinter with basicity = 2.3 reduced at $900{ }^{\circ} \mathrm{C}$ for $3 \mathrm{~h}$. It can be observed that the iron oxide was reduced to metallic iron (area 1). The gangue phases (areas 2 and 3), which were hard to be reduced still existed in the reduced HCVTM sinter. 


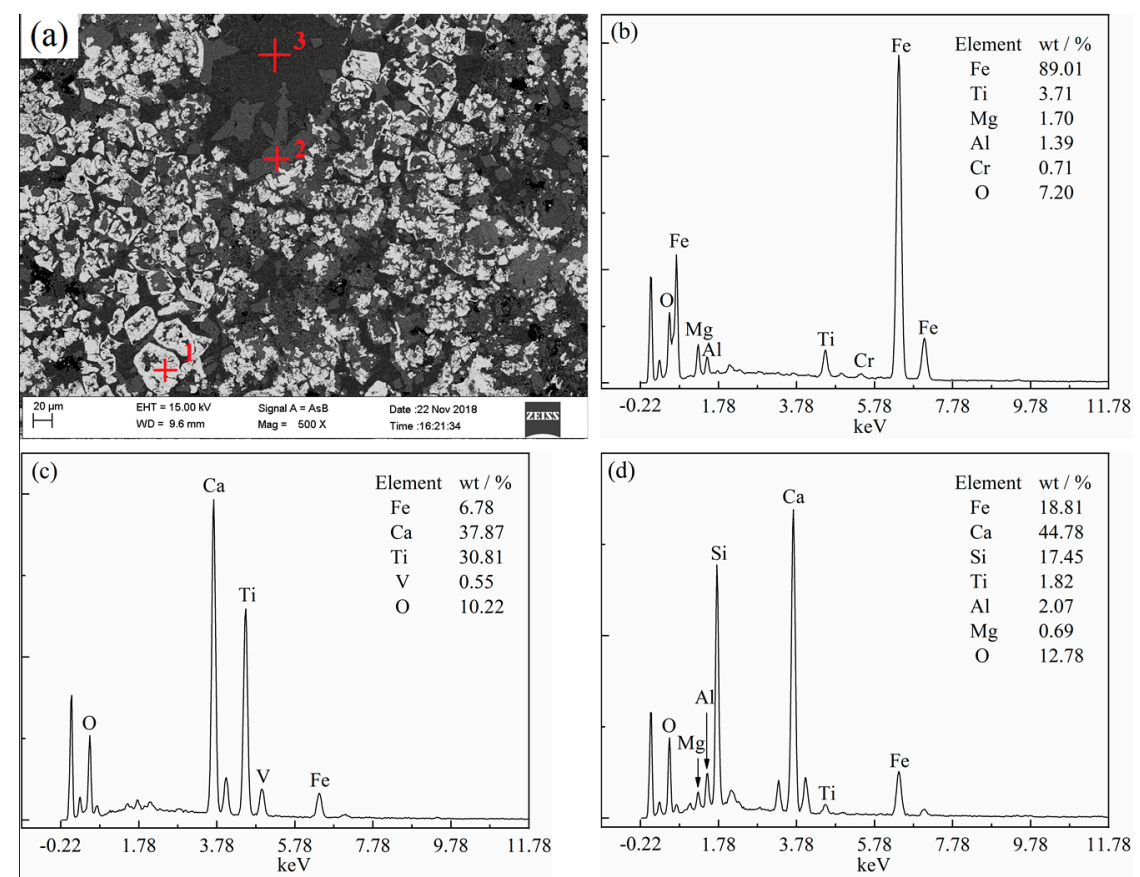

Figure 9. SEM image and EDS analysis of sinter after reduction at $900^{\circ} \mathrm{C}$ for $3 \mathrm{~h}$ (basicity $=2.3$ ). (a) SEM image; (b) point 1 ; (c) point 2; (d) point 3.

\subsection{Effect of Basicity on Softening-Melting Properties}

Figure 10 shows the softening-melting properties of the HCVTM sinter with different basicity. The $\mathrm{T}_{10 \%}$ increased from 1091 to $1112{ }^{\circ} \mathrm{C}$ and the $\mathrm{T}_{40 \%}$ increased from 1158 to $1184{ }^{\circ} \mathrm{C}$ with the basicity increase. The $\Delta \mathrm{T}_{1}$ increased from 67 to $72{ }^{\circ} \mathrm{C}$. The $\mathrm{T}_{\mathrm{s}}$ decreased from 1241 to $1233^{\circ} \mathrm{C}$ and $\mathrm{T}_{\mathrm{d}}$ decreased from 1431 to $1429{ }^{\circ} \mathrm{C}$ with the basicity increase. The $\Delta \mathrm{T}_{2}$ decreased from 210 to $196^{\circ} \mathrm{C}$. The $\Delta \mathrm{P}_{\mathrm{m}}$ increased from 10.6 to $14.5 \mathrm{kPa}$.
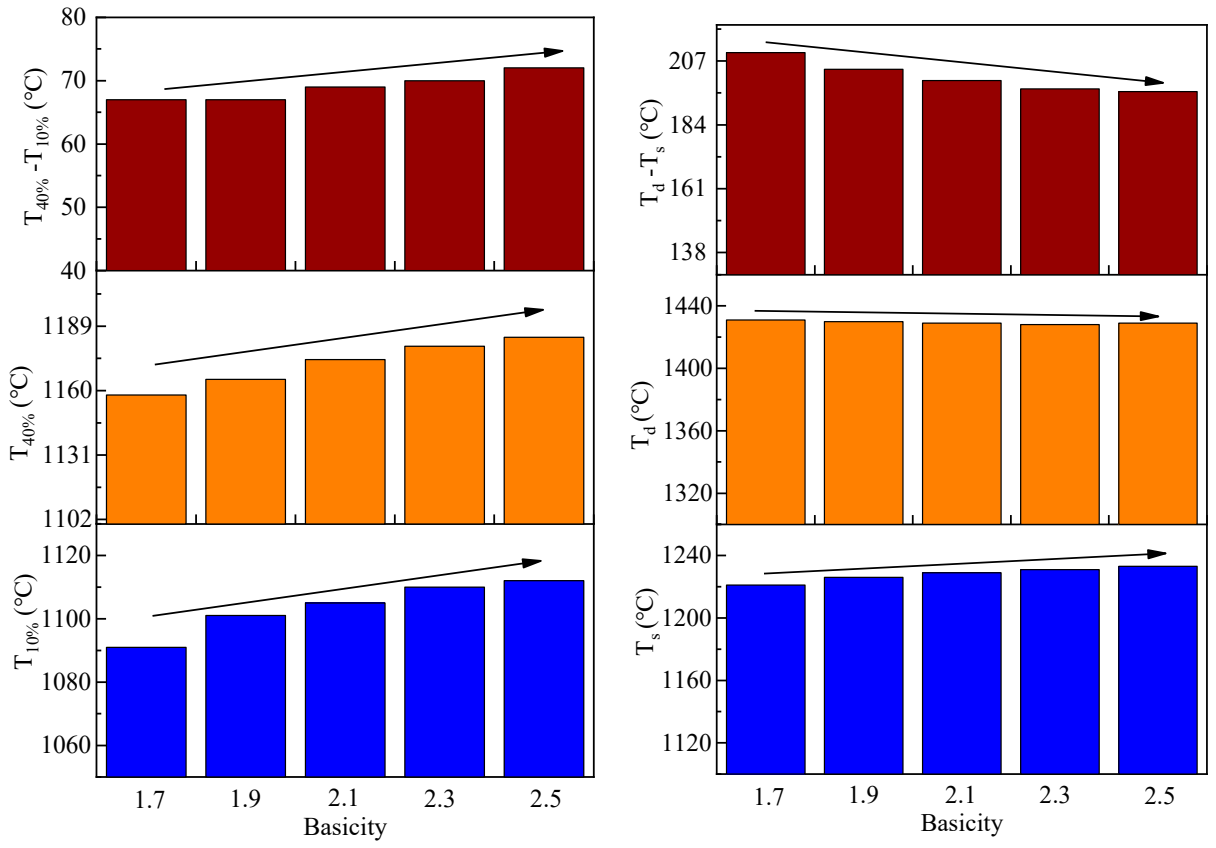

Figure 10. Sinter softening-melting properties with different basicity.

A high $\mathrm{T}_{10 \%}$ and an applicable scale of $\Delta \mathrm{T}_{1}$ are favorable to the reduction reactions of iron ore for sinter softening in the BF [20]. The HCVTM sinter has a better tendency of the softening behavior 
with the basicity increase, since $\mathrm{T}_{10 \%}$ mainly depends on the melting point of the low-melting slag phase. After the basicity increased, the amounts of minerals with good reducing properties, such as calcium ferrite, increased, and the titanohematite and titanomagnetite content decreased. What is more, some magnetite was oxidized to hematite to form calcium ferrite, and the reducing property was significantly improved. Under the same reducing conditions, more $\mathrm{FeO}$ will be reduced to metallic iron, and $\mathrm{FeO}$ entering the slag will be correspondingly reduced, thus causing the melting point of the slag phase and $\mathrm{T}_{10 \%}$ to rise. As the basicity increased, the softening interval shortened, which helped improve the gas permeability of the softening-melting zone of the BF.

The $T_{S}$ increased with the increase of the perovskite phases. The $T_{D}$ depended on the melting point of the slag phase and the metal carburizing reaction. With the FeO decrease and the RI increase, the $T_{D}$ decreased slightly. Therefore, the droplet interval became shorter, that is, the droplet belt thickness reduced, thus reducing the loss of permeability resistance, which was conducive to the stable operation and strengthening of the BF. The smaller thickness of the melting zone and the narrower droplet temperature range were beneficial to the BF operation. However, as the basicity increased, the column pressure difference increased, and the melt droplet comprehensive index value deteriorated. This was because the $\mathrm{SiO}_{2}$ content did not change during the sinter process. As the basicity further increased, the amount of quicklime increased. During the sinter process, the $\mathrm{CaO}$ was more easily combined with $\mathrm{TiO}_{2}$ to form perovskite. Perovskite was difficult to be reduced during the soft-melt dripping process because of its high melting point and stability. Therefore, the soft-melt dripping belt had a great influence on the dripping performance of the charge, which eventually led to an increase in the column pressure difference.

Figure 11 shows the indexes including the $\Delta \mathrm{P}_{\mathrm{m}}$ and $\mathrm{S}$. The $\Delta \mathrm{P}_{\mathrm{m}}$ increased from 10.6 to $14.5 \mathrm{kPa}$. According to Equation (8), the $\mathrm{S}$ value increased from 2123 to $2746 \mathrm{kPa} \cdot{ }^{\circ} \mathrm{C}$. In general, the $\mathrm{S}$ value of the softening-melting properties of the sinter is mainly used to evaluate the gas permeability index of the sinter. The smaller the $S$ value becomes, the better the gas permeability index of the sinter will be [21]. As a result, the permeability deteriorated with the increase of basicity.

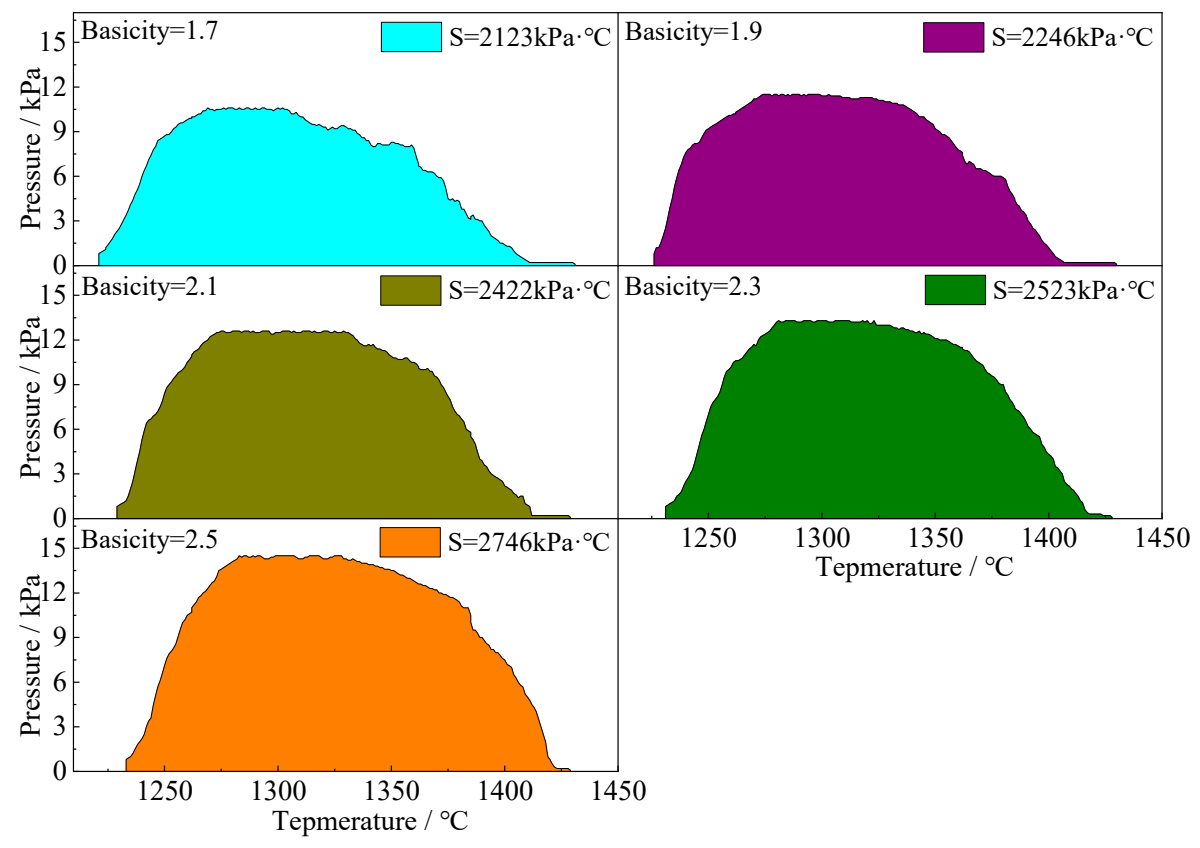

Figure 11. Effect of basicity on the gas permeability of HCVTM sinters.

\subsection{Comprehensive Index}

The best outcomes for the key parameters were achieved at different basicity values, making it necessary to devise a composite index [22]. 
The first set of composite indices are used for reference and quantified to 100 for comparison and analysis. Based on years of experience in the production of vanadium-titanium magnetite, Jianlong Steel has determined the selected indicators (sinter rate, yield, strength, RDI, and RI) and the significance coefficient. The total significance coefficient was 100, and the sinter rate, yield, productivity, TI, RDI, and RI significance coefficients were 5, 25, 10, 20, 20, and 20, respectively.

Define

$$
R_{j}=\left(z_{i j}\right)_{\max }-\left(z_{i j}\right)_{\min }
$$

where $R_{j}$ is the range, $z_{i 1}$ is the VSS, $z_{i 2}$ is the productivity, $z_{i 3}$ is the yield, $z_{i 4}$ is the TI, $z_{i 4}$ is the RDI, and $z_{i 5}$ is the RI.

$$
w_{j}=W_{j} / R_{j}
$$

where $w_{j}$ is the unit range coefficient, and $W_{j}$ is the significance coefficient.

$$
\begin{gathered}
f_{i}=\sum_{j=1}^{m} w_{j} z_{i j}(i=1,2, \cdots, m) \\
F_{i}=f_{i}-f_{1}+100
\end{gathered}
$$

where $F_{i}$ is the comprehensive index, and $f_{i}$ is the composite index.

Table 4 shows the calculation process of the comprehensive index value. Figure 12 shows the comprehensive index. As the basicity increased from 1.7 to 2.5 , the comprehensive index value increased from 100 to 183.33 . There was a large increase from 1.7 to 2.3 and only a very small increase from 2.3 to 2.5 . Considering the adverse effect of basicity on softening-melting properties, the best recommended value is 2.3 .

Table 4. Calculation process of the comprehensive index.

\begin{tabular}{ccccccccc}
\hline Basicity / \% & $z_{i 1}$ & $z_{i 2}$ & $z_{i 3}$ & $z_{i 4}$ & $z_{i 5}$ & $z_{i 6}$ & $f_{i}$ & $F_{i}=f_{i}-f_{1}+\mathbf{1 0 0}$ \\
\hline 1.7 & 15.81 & 1.33 & 71.17 & 47.3 & 69.9 & 74.2 & 789.15 & 100 \\
1.9 & 16.19 & 1.50 & 75.70 & 46.7 & 71.8 & 75.1 & 810.56 & 121.42 \\
2.1 & 15.81 & 1.43 & 81.74 & 46.0 & 80.5 & 76.6 & 819.41 & 130.26 \\
2.3 & 17.44 & 1.61 & 80.63 & 48.7 & 84.7 & 80.2 & 869.19 & 180.04 \\
2.5 & 17.89 & 1.54 & 79.00 & 49.3 & 86.3 & 81.9 & 872.48 & 183.33 \\
$R_{j}$ & 2.08 & 0.28 & 10.57 & 3.3 & 16.4 & 7.7 & - & - \\
$W_{j}$ & 5 & 25 & 10 & 20 & 20 & 20 & - & - \\
$\omega_{j}$ & 2.40 & 89.29 & 0.95 & 6.06 & 1.22 & 2.60 & - & - \\
\hline
\end{tabular}

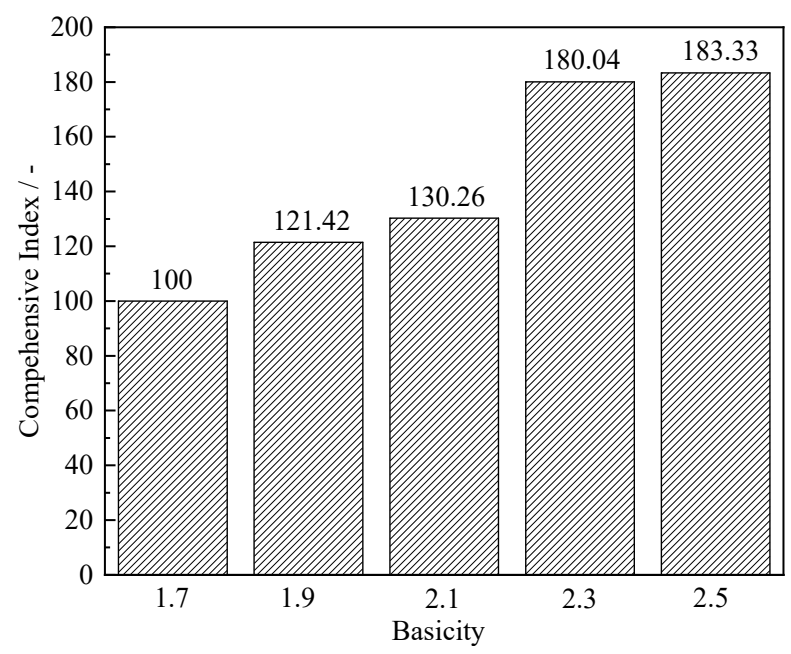

Figure 12. Effect of basicity on the comprehensive index of HCVTM sinters. 


\section{Conclusions}

(1) When the basicity increased from 1.7 to 2.5 , the vertical sinter speed, the productivity, the particle size, the RDI, and the RI increased. The yield increased first and then decreased, while the TI had the opposite trend.

(2) Titanomagnetite and titanohematite were the main minerals in the sinter. As the basicity increased, the perovskite content level stabilized, while the SFCA increased from the basicity of 2.3.

(3) The HCVTM sinter had a better tendency of the softening behavior with the basicity increase. In addition, the melt droplet comprehensive index $S$ increased, which indicated that the increase in basicity negatively affected the droplet performance.

(4) As the basicity increased, the comprehensive index value increased. Considering the adverse effect of basicity on softening-melting properties, the best recommended value is 2.3.

Author Contributions: Conceptualization, X.X. and L.Z.; methodology, S.Y.; validation, X.X., S.Y. and L.Z.; formal analysis, Z.G.; investigation, W.T.; resources, X.X.; data curation, Z.G.; writing-original draft preparation, L.Z.; writing-review and editing, L.Z.; supervision, X.X.; project administration, X.X.; funding acquisition, X.X. All authors have read and agreed to the published version of the manuscript.

Funding: This research was funded by the National Basic Research Program of China (973 Program) (no. 2013CB632603), the National Key Technology R\&D Program (no. 2015BAB19B02), the National Natural Science Foundation of China (nos. 51090384, 51174051, and 51574082), and the Fundamental Research Funds for the Central Universities (no. N182503035).

Conflicts of Interest: The authors declare no conflict of interest.

\section{References}

1. Cheng, G.-J.; Xue, X.-X.; Gao, Z.-X.; Jiang, T.; Yang, H.; Duan, P.-N. Effect of Cr2O3 on the Reduction and Smelting Mechanism of High-Chromium Vanadium-titanium Magnetite Pellets. ISIJ Int. 2016, 56, $1938-1947$. [CrossRef]

2. Jena, B.; Dreßler, W.; Reilly, I. Extraction of titanium, vanadium and iron from titanomagnetite deposits at pipestone lake, Manitoba, Canada. Miner. Eng. 1995, 8, 159-168. [CrossRef]

3. Takano, C.; Zambrano, A.P.; Nogueira, A.E.A.; Mourao, M.; Iguchi, Y. Chromites Reduction Reaction Mechanisms in Carbon-Chromites Composite Agglomerates at 1773 K. ISIJ Int. 2007, 47, 1585-1589. [CrossRef]

4. Lu, C.-Y.; Zou, X.; Lu, X.-G.; Xie, X.-L.; Zheng, K.; Xiao, W.; Cheng, H.; Li, G.-S. Reductive kinetics of Panzhihua ilmenite with hydrogen. Trans. Nonferrous Met. Soc. China 2016, 26, 3266-3273. [CrossRef]

5. Fu, W.-G.; Wen, Y.-C.; Xie, H.-E. Development of Intensified Technologies of Vanadium-Bearing Titanomagnetite Smelting. J. Iron Steel Res. Int. 2011, 18, 7-10. [CrossRef]

6. Fu, W.G.; Xie, H.E. Progress in Technologies of Vanadium-Bearing Titanomagnetite Smelting in PanGang. Steel Res. Int. 2011, 82, 501-504. [CrossRef]

7. Umadevi, T.; Bandopadhyay, U.; Mahapatra, P.; Prabhu, M.; Ranjan, M. Influence of limestone particle size on iron ore sinter properties and productivity. Steel Res. Int. 2010, 81, 419-425. [CrossRef]

8. Wang, H.-T.; Zhao, W.; Chu, M.-S.; Wang, R.; Liu, Z.-G.; Xue, X.-X. Effect and function mechanism of sinter basicity on softening-melting behaviors of mixed burden made from chromium-bearing vanadium-titanium magnetite. J. Central South Univ. 2017, 24, 39-47. [CrossRef]

9. Yu, Z.; Li, G.; Jiang, T.; Zhang, Y.; Zhou, F.; Peng, Z. Effect of Basicity on Titanomagnetite Concentrate Sintering. ISIJ Int. 2015, 55, 907-909. [CrossRef]

10. Umadevi, T.; Sah, R.; Mahapatra, P.C. Influence of sinter basicity (CaO/SiO 2$)$ on low and high alumina iron ore sinter quality. Miner. Process. Extr. Met. 2014, 123, 75-85. [CrossRef]

11. Zhou, M.; Yang, S.-T.; Jiang, T.; Xue, X. Influence of Basicity on High-Chromium Vanadium-Titanium Magnetite Sinter Properties, Productivity, and Mineralogy. JOM 2015, 67, 1203-1213. [CrossRef]

12. Zhang, L.; Yang, S.-T.; Tang, W.; Xue, X.-X. Investigations of MgO on Sintering Performance and Metallurgical Property of High-Chromium Vanadium-Titanium Magnetite. Minerals 2019, 9, 324. [CrossRef] 
13. Zhang, L.; Yang, S.; Tang, W.; Yang, H.; Xue, X.-X. Effect of coke breeze content on sintering mechanism and metallurgical properties of high-chromium vanadium-titanium magnetite. Ironmak. Steelmak. 2019, 1, 1-7. [CrossRef]

14. Zhu, D.; Zhang, K.-C.; Pan, J.; Fan, X.-H.; Hu, Y.-M.; John, C. Effect of fluxes on high iron and low silica sintering. J. Central South Univ. Technol. 2003, 10, 177-182. [CrossRef]

15. Kasai, E.; Sakano, Y.; Kawaguchi, T.; Nakamura, T. Influence of Properties of Fluxing Materials on the Flow of Melt Formed in the Sintering Process. ISIJ Int. 2000, 40, 857-862. [CrossRef]

16. Xue, M.; Guo, X. Effect of $\mathrm{Al} 2 \mathrm{O} 3$ and $\mathrm{SiO} 2$ on formation and crystal structure of calcium ferrite containing Al2O3 and SiO2. J. Chin. Rare Earth Soc. 2008, 26, 205.

17. Zhang, G.-L.; Wu, S.; Su, B.; Que, Z.-G.; Hou, C.-G.; Jiang, Y. Influencing factor of sinter body strength and its effects on iron ore sintering indexes. Int. J. Miner. Met. Mater. 2015, 22, 553-561. [CrossRef]

18. Chen, Y.M.; Chen, R. Microstructure of Sinter and Pellet; Cental South University Press: Changsha, China, 2011; p. 63. (In Chinese)

19. Kawaguchi, T.; Hara, M. Utilization of Biomass for Iron Ore Sintering. ISIJ Int. 2013, 53, 1599-1606. [CrossRef]

20. Ma, J.Y.; Sun, X.W.; Sheng, S.X. Intensified smelting of vanadium and titanium magnetite in blast furnace. Iron Steel. 2000, 35, 4-7.

21. Qie, J.; Zhang, C.; Li, X.; Guo, Y.; Wang, H.; Wu, S. Lower SO2 Emissions in the Sintering Process Utilizing the Difference of Sulphur Contents of Iron Ores. ISIJ Int. 2017, 57, 2115-2123. [CrossRef]

22. Zhou, M.; Yang, S.-T.; Jiang, T.; Xue, X.-X. Corrigendum: Influence of MgO in form of magnesite on properties and mineralogy of high chromium, vanadium, titanium magnetite sinters. Ironmak. Steelmak. 2015, 42, 320. [CrossRef]

(C) 2020 by the authors. Licensee MDPI, Basel, Switzerland. This article is an open access article distributed under the terms and conditions of the Creative Commons Attribution (CC BY) license (http://creativecommons.org/licenses/by/4.0/). 